\title{
Through Thickness Residual Stress and Microstructural Mapping of AA7085-T7452 Die Forging
}

\author{
P. S. Baburamani ${ }^{\star a}$, K. F. Walker ${ }^{\text {b }}$, P. K. Sharp ${ }^{\text {c }}$, J. Niclis ${ }^{d}$ and A. Shekhter ${ }^{\text {e }}$ \\ Aerospace Division, Defence Science and Technology Group, Fishermans Bend, Vic 3207 \\ ${ }^{*}$ Corresponding author: E-mail: ${ }^{a}$ pud.baburamani@dsto.defence.gov.au; \\ bkevin.walker@dsto.defence.gov.au; ${ }^{\mathrm{b}}$ khan.sharp@dsto.defence.gov.au;

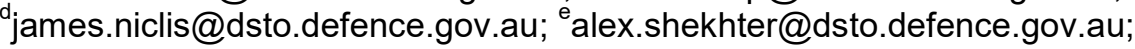

Keywords: Forging, Slitting, Microstructure, Through-thickness, Residual Stress, Hardness

\begin{abstract}
Significant weight savings and reductions in manufacturing costs have motivated the drive towards the use of unitised structures such as large die forgings in modern aircraft. However, detrimental bulk tensile residual stresses, present in these thick forgings can impact the durability and structural integrity of the primary aerospace structure. Residual stresses can lead to distortion during component machining, and part rejection. In addition, failure to account for the residual stress effects in the fatigue crack growth characteristics of the component in design and in performance could impact the structural integrity. Therefore, there is a need to measure and analyse the residual stresses present in the forged components, and examine the residual stress-microstructure, including grain structure/flow relationship for the forging, if such a relationship could be developed. The preliminary results of this experimental program have shown a link between the measured residual stress and hardness, along with changes in the grain structures through the thickness.
\end{abstract}

\section{Introduction}

Structural unitisation of components is being actively pursued by the aerospace industry with the primary aim of weight reduction and cost savings. Large aluminium forgings and thick section rolled products make a significant contribution towards unitisation of critical, primary airframe components, such as wing-carry-through bulkheads. Inherent with the thick section wrought product forms, and particularly in die forged components, is the built-in bulk residual stresses on a macro scale [1], arising from the thermal gradients in the thermo-mechanical processing and the postsolution treatment rapid quenching. The presence of process related bulk residual stresses results in: a) part distortion during machining which is a cost driver and b) high degree of scatter and/or variability in fatigue crack growth rate [2], which is a performance driver affecting the durability and damage tolerance of the component. The residual stresses in an aluminium 7050-T7452 forged block that caused distortion during machining was reported to be a major cost driver for a commercial aircraft manufacturer, as a result of excess manufacturing time, schedule overruns, and part rejection and scrapped material [3].

The surface and subsurface compressive residual stresses in an as-quenched (before stress relief treatment) aluminium alloy forgings have been reported to be in the range -200 $\mathrm{MPa}-250 \mathrm{MPa}$ [4]. The mechanical stress relief treatment by cold compression (forgings) or stretching (rolled plate) that follows, aims to relieve (or reduce) the severity of the bulk residual stresses existed in the asquenched state in the component. However, cold compression stress relief in die forged components do not always fully relieve the complex $3 \mathrm{D}$ bulk residual stresses, and the unrelieved residual stresses may be of sufficient magnitude to cause distortion in machined components [4-6]. Moreover, the three dimensional residual stress distribution in the stress relieved aluminium die forging varied 
with the position, and the geometry of the forging, as a result of varying thermal gradients and the plastic flow in the three orthogonal directions [4].

As a first step towards a better understanding of the residual stresses in thick sections, a preliminary experimental program was carried out to measure the residual stresses present in the open die forged, mechanically stress relieved, thick AA7085-T7452 aluminium (Al-Zn-Mg-Cu-Zr) alloy, and examine if a residual stress-microstructure relationship for the forged material, can be developed. The objective of the work reported here was to measure the residual stress profile using $\mathrm{X}$-Ray diffraction and by the slitting method on samples cut from various depths and transverse positions, and along the through-thickness, to correlate the results with the grain flow, microstructure and hardness.

\section{Experimental Methods and Materials}

AA7085-T7452 aluminium alloy open die forging, which had been compression stress relieved and, measuring $1750 \mathrm{~mm}$ (length) x $1200 \mathrm{~mm}$ (width) x $152 \mathrm{~mm}$ (thickness) was used in this study. The samples B1, B2, B3, B4 and B5 $(80 \mathrm{~mm} \times 25 \mathrm{~mm} \times 10 \mathrm{~mm})$ were taken from five locations at the centre along the through thickness direction of the open die forging and were used in the $\mathrm{x}$-ray diffraction residual stress measurements and, for hardness measurements and microstructural examination (See Fig. 1). The specimens were without any surface irregularities, and had a smooth surface finish, close to N6.

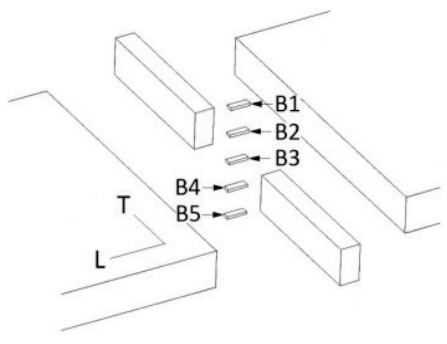

Figure 1 Specimen cut up diagram for B1, B2, B3, B4 and B5 from the open die forging

The microstructures were characterised using standard metallographic procedures in the longitudinal and short transverse surfaces of the samples. Hardness measurements were taken at five locations in the sample using a Rockwell hardness tester and on the B-scale using $100 \mathrm{~kg}$ load. XRay diffraction (XRD) was performed using a Proto iXRD Combo with a Cobalt X-Ray source and using a $2 \mathrm{~mm}$ circular aperture or $1.0 \times 5 \mathrm{~mm}$, or $2.0 \times 5 \mathrm{~mm}$ aperture. In addition, four larger samples of $80 \mathrm{~mm} \times 25 \mathrm{~mm} \times 25 \mathrm{~mm}$, identified B1/2, B2/3, B3/4 and B4/5 were sent to Hill Engineering, California for residual stress measurements by the slitting method [7], to obtain through-thickness residual stress distribution at those locations. Sample B1/2 was located between $\mathrm{B} 1$ and $\mathrm{B} 2$, and B2/3 was located between B2 and B3 and so forth. These larger samples were thought to be relatively more representative of the through-thickness locations in the forging for that heat treated temper. The material elastic properties used by Hill Engineering in the residual stress calculations were; Young's modulus $=71.7 \mathrm{GPa}$ and the Poisson's ratio, $v=0.33$ [7]. Prior to the slitting measurements, the back side of the rectangular specimens was skimmed using EDM wire to provide a flat surface to mount the strain gage. The specimens were slit at the approximate midlength using a wire EDM along the sample thickness direction. A single strain gage was mounted to the back face of the specimens, behind the slit. The measured strain versus slit depth was used to calculate the residual stress [7].

\section{Results and Discussion}

Hardness. The through-thickness hardness was measured in the longitudinal and the short transverse surfaces of the specimens B1, B2, B3 and B5 (Fig. 1), and the mean values are shown in Table 1. The specimen locations $x(B 1, B 2$, etc.) relative to the forging thickness $t(152 \mathrm{~mm}), x / t$ are also indicated 
in the table. The standard deviations for the hardness in the longitudinal surface were 0.3 to 0.9 and for the short transverse direction 0.1 to 0.6 .

Table 1 Rockwell hardness (HRB) in the longitudinal and short transverse surfaces

\begin{tabular}{|c|c|c|c|}
\hline Specimen & Location, $\mathbf{x} / \mathbf{t}$ & HRB Mean-Longitudinal & HRB Mean-Short transverse \\
\hline B1 & 0.03 & 86.0 & 87.6 \\
\hline B2 & 0.27 & 84.8 & 85.0 \\
\hline B3 & 0.50 & 83.5 & 80.7 \\
\hline B5 & 0.97 & 87.4 & 87.4 \\
\hline
\end{tabular}

The hardness reached its maximum values near the top (B1) and bottom (B5) surface locations in the forging, in both directions, and as we approach the centre of the forging, the hardness is seen to decrease, reaching a minimum value at the centre (B3), in both the longitudinal and short transverse surfaces (Table 1). This trend may be attributed to less deformation and slow cooling at the centre in the thick section forging, leading to lower work hardening and lower flow stress as suggested by Robinson et al. [8], compared to the top and bottom surfaces which can absorb more deformation and cool faster. This trend is more strongly observed in the short transverse direction (see Figure 2). Also note the differences in the hardness results for B3 which is at the centre (core) of the forging; the short transverse hardness is lower than the longitudinal hardness, an indication of the inhomogeneity present in the thick forging. Zhang et al. [5], examined the through-thickness hardness distribution in the centre of the specimen in a $121 \mathrm{~mm}$ thick 7050-T7452 forging and a minimum value of hardness occurred at one end of the specimen near the surface, corresponding to a low value of tensile or compressive residual stress and a maximum hardness at the centre of the specimen. These results differ from the trends observed in the present work, the sample size and the extent of deformation and the thermal gradients could determine the actual trend observed. The through-thickness hardness and through thick residual stress appeared to follow the same trend in their work [5], and a similar trend is also seen in this work (Fig. 2). Figure 2 compares the near-surface residual stresses measured by the slitting method and by X-ray diffraction with the Rockwell hardness measured in the short transverse and longitudinal surfaces, respectively. The hardness measured in the short transverse faces of B1, B2, B3 and B5 appear to nearly relate to the through thickness residual stresses measured near the surface on samples B1/2, B2/3, B3/4 and B4/5 by the slitting method (Fig. 2).

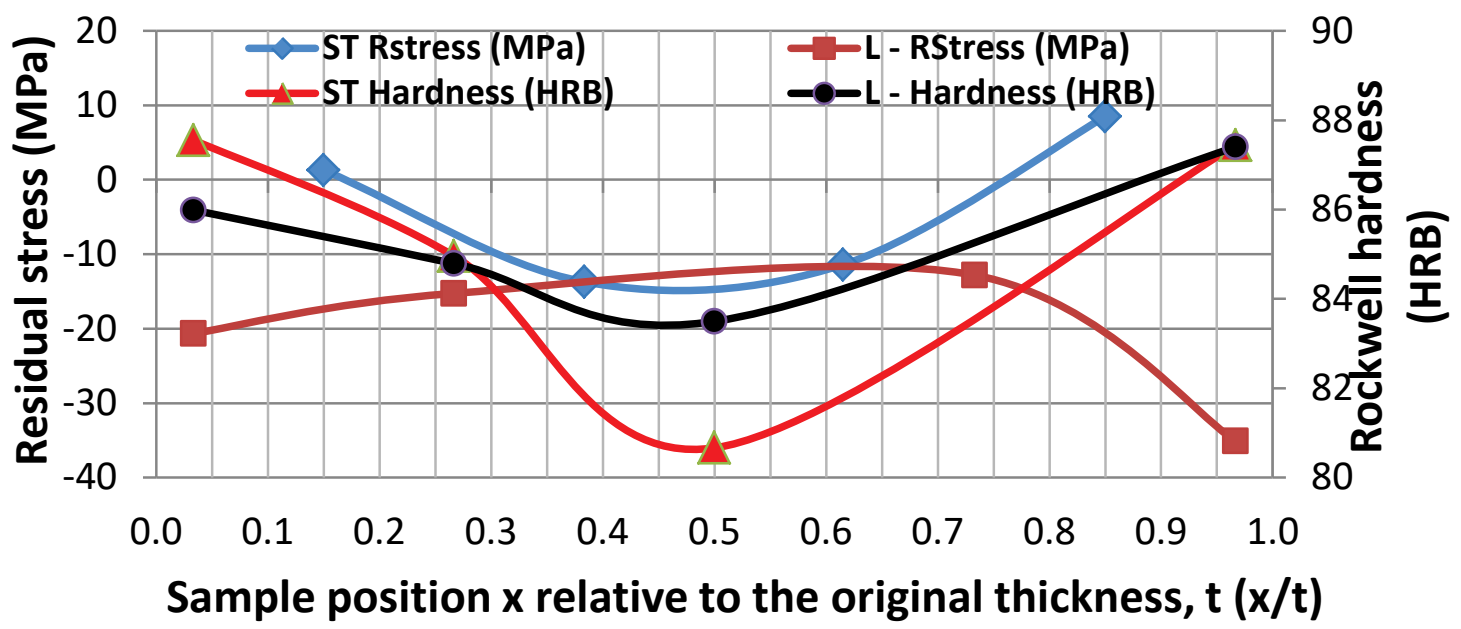

Figure 2 Residual stress and hardness in the longitudinal and short transverse surfaces 
Through-Thickness Residual Stresses. Fig. 2 also shows the distribution of residual stresses at the centre of the longitudinal surface of the specimens measured by x-ray diffraction and the residual stress close to the surface at a depth of $0.03 \mathrm{~mm}(30 \mu \mathrm{m})$ measured by the slitting method and, the average hardness values measured on the same longitudinal and short transverse surfaces, respectively. Overall, the measured XRD residual stresses were low $(<35 \mathrm{MPa})$ and compressive in all the sample surfaces, and in through the thickness of the forging. The residual stresses are more compressive (20 to $35 \mathrm{MPa}$ ), near the top and the bottom surfaces and less compressive (12 to 15 $\mathrm{MPa}$ ) in the interior regions of the samples from the forging. The mean error or uncertainty in the XRD residual stress measurements was $7.5 \mathrm{MPa}$ and the range was 4 to $12 \mathrm{MPa}$. This kind of variations in the residual stresses measured has also been reported in the literature [5]. The longitudinal residual stresses in the cold compressed forging were reported to vary with the position along the length of the forging due to multiple compression and overlap [3], during post-quench cold compression stress relief [5].

The relatively low values of residual stresses are possibly due to the original forging (and hence the samples) was solution treated, rapidly cooled and cold compression stress relieved at $\sim 1.5 \%$ to $3 \%$ plastic strain, and subsequently age hardened, and also possibly due to the samples being put through a number of cutting operations to produce the smaller sample sizes used in these experiments. It is more than likely; each cutting or machining operation would relieve some of the residual stresses [9].

However, these observations are similar to those of Robinson et al. [10]. In their work [10], 7050 aluminium forging was investigated. The surface residual stress was compressive and around 40 $\mathrm{MPa}$, after overageing. The residual stresses had dropped from about -200 to $-220 \mathrm{MPa}$ in the as cold water quenched state to -50 to $-70 \mathrm{MPa}$ after cold compression (stress relief), and to -40 to $-50 \mathrm{MPa}$ after overageing. Figure 2 also includes hardness to show how it compares with the residual stress measurements. It can be seen that higher residual stresses (XRD) near the top and bottom ends ( -20 $\mathrm{MPa}$ and -35 MPa) aligns with higher hardness results (86.0 and 87.4 HRB). As the residual stresses show a decrease towards the core inner regions of the forging (-12 and $-15 \mathrm{MPa})$, the hardness numbers also decrease ( 84.8 and $83.5 \mathrm{HRB}$ ) on the longitudinal surfaces.

The uncertainties in the residual stress measurements by the slitting method were 0.8 to 1.2 [7]. The residual stresses and the hardness follow similar trends as those observed for the longitudinal surface hardness and XRD surface residual stresses. Note that in Figure 2, all the residual stresses are compressive, for XRD, and the residual stresses are tensile near the top (B1/2) and bottom surfaces (B4/5) [1.3 $\mathrm{MPa}$ and 8.5 MPa] and, compressive in the inner regions in the slitting method. The observed trends in Figure 2 for the measured residual stresses (slitting) and the short transverse surface hardness are more closely aligned suggesting a potential intrinsic relationship between the two parameters. Zhang et al [5] commented that the through thickness residual stress profiles and the spatial variation in stress distribution are likely to have been caused by the non-uniform plastic deformation during the stress relief treatment.

Through-Thickness Microstructures. The through-thickness microstructures were assessed from samples B1, B2, B3, B4 and B5 taken from different locations from the surfaces, interiors and the core of the forging in the short transverse (through the $152 \mathrm{~mm}$ thickness) direction. These surfaces correspond to the direction in which the slitting operations were performed in samples B1/2, B2/3, $\mathrm{B} 3 / 4$ and $\mathrm{B} 4 / 5$. The representative microstructures, as marked, and the residual stress distribution obtained from the slitting method [Fig. 3 (d)], are shown in Figure 3. 


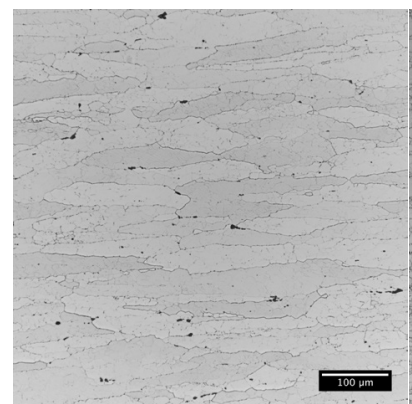

(a) B1

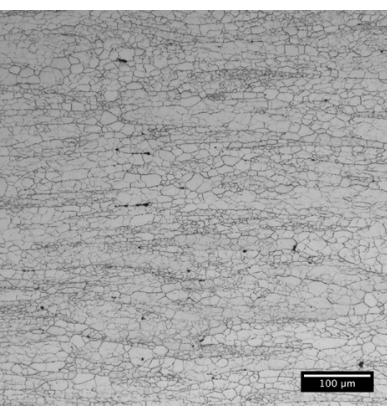

(b) B2 (c) B3

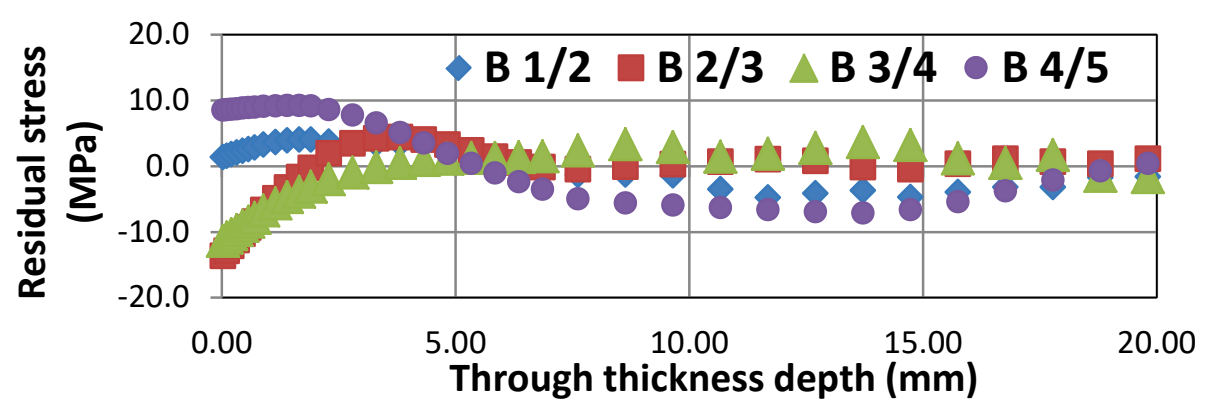

(d)

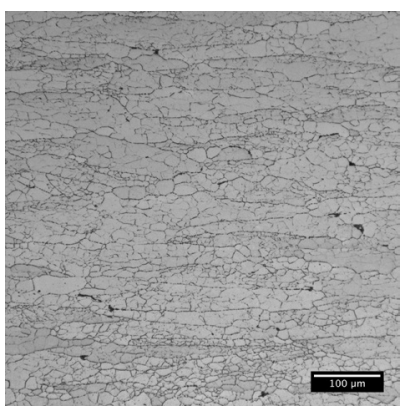

(e) B4

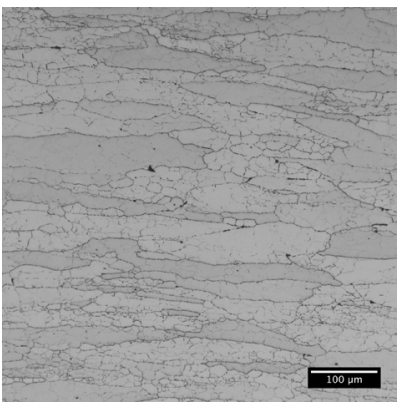

(f) B5

Figure 3 Through-thickness residual stresses measured by the slitting method (d) and the microstructures of specimens in the short transverse direction; (a) B1, (b) B2, (c) B3, (e) B4 and (f) $B 5$

The microstructures showed a dual grain structure consisting of elongated large grains, and smaller, polygonised grains in un-recrystallised and partially recrystallised forms. For example, close to the surface, B1 and B5, where more deformation is likely during mechanical working and during compressive stress relief, large, elongated and worked grain structure with very few polygonised grains are shown, [Fig. 3 (a) and 3 (f)]. In B2, there is a mixture of elongated grains and large polygonised or equi-axed grains that appear to be partially recrystallised [Fig. 3 (b)]. In B3, which is at the core there is less deformation during the thermo-mechanical processing stage and it is likely to retain more heat compared to the top and bottom surfaces because it cools slowly, there are elongated grains that do not appear to be severely worked and with a large number of small sub grains [Fig. 3 (c)]. B4 is an extension of B3 but showing more worked structure and larger sub grains [Fig. 3 (e)], possibly because it receives more deformation than B3. Variations and inhomogeneous grain distributions through the samples at various positions along the through-thickness of the forging are evident in these micrographs, in line with the heterogeneous grain distribution observed in aluminium alloy forgings reported in the literature [10]. The microstructures in the thick section die forging have evolved during the thermo-mechanical/metallurgical processing, and the nature of the 
grain structure is dependent mainly on the amount of working the various regions in the throughthickness face are subject to, and the thermal gradients. The larger (coarser) grains near the top (B1, Fig. 3 a) and bottom (B5, Figure 3 f) surfaces have resulted in slightly higher hardness values (see Table 1 and Fig. 2). In general, any mutual dependency between grain distribution and size, and the residual stresses is likely to be governed by the thermal gradients and deformation inhomogeneities during mechanical working and compressive deformation stress relief, and the strain hardening behaviour of the material in the production of thick section forged products and components.

\section{Conclusion}

The preliminary experimental work and the results reported in this paper have identified the nature and extent of non-uniform contours in the residual stresses in the thick section forged product and, the inhomogeneous microstructural features present in the forging. In addition, the results present another dimension in the inhomogeneity space in terms of grain structure and size, as well as variations in hardness and, potentially indicative of varying strength and fatigue properties in the final component. The observed trends in Fig. 2 for the measured residual stresses by the slitting method and the surface hardness are more closely aligned, suggesting a potential intrinsic relationship between the two parameters. Slitting method provides through the thickness profile of residual stress with depth, the surface and the interiors of the specimens provide different type of contours, which confirms the inhomogeneous distribution of residual stresses in thick section aluminium alloy products. Results from XRD and slitting methods showed that relatively higher residual stresses at the top and bottom of the samples were aligned with higher hardness values and interior and core regions showed lower residual stresses and lower hardnesses. The work hardening capability of the section through the thickness and the thermal and deformation gradients are thought to be one of the factors responsible for the observed results. The preliminary experiments and the results have provided an opportunity to explore these aspects further, with the use of more representative larger samples to start with.

\section{References}

[1] G. S. Wilson, A. F. Grandt Jr., R. J. Bucci, R. W. Schultz, Int. J. Fatigue, 31 (2009) 1286-1299. http://dx.doi.org/10.1016/j.ijfatigue.2009.02.023

[2] R. W. Bush, R. J. Bucci, P. E. Magnusen, G. W. and Kuhlman, ASTM STP 1189, Ravinder Chona (Ed.), American Society for Testing and Materials, Philadelphia, 1993 568-589.

[3] D. M. Walker and R. Y. Hom, Advanced Materials and Processes, 1606 (2002), 57-60.

[4] J. S. Robinson, S., Hossain, C. E. Truman, A. M. Paradowska, D. J. Hughes, R. C. Wimpory, M.

E. Fox, Materials Science and Engineering A, $527 \quad$ (2010) 2603-2612. http://dx.doi.org/10.1016/j.msea.2009.12.022

[5] Z. Zhang, Y. Yang, L. Li, B. Chen, H. Tian, Materials Science and Engineering A, 644 (2015) 61-68. http://dx.doi.org/10.1016/j.msea.2015.07.018

[6] M. B. Prime, and M. R. Hill, Scripta Materialia, 46 (2002) 77-82. http://dx.doi.org/10.1016/S1359-6462(01)01201-5

[7] A. T. DeWald, Measurement report, Hill Engineering, LLC, California, 2016, 6p.

[8] J. S. Robinson, C. E. Truman, S. Hossain, R. Wimpory, Materials Science Forum, 571-572 (2008) 45-50. http://dx.doi.org/10.4028/www.scientific.net/MSF.571-572.45

[9] Altenkirch, J., Steuwer, A., Peel, M., Richards, D. G., Withers, P. J., The effect of tensioning and sectioning on residual stresses in aluminium AA7749 friction stir welds, Materials Science and Engineering A, 488 (2008) 16-24. http://dx.doi.org/10.1016/j.msea.2007.10.055

[10] J. S. Robinson, P. J. Tiernan and J. F. Kelleher, Materials Science and Technology, 314 (2015) 409-417. http://dx.doi.org/10.1179/1743284714Y.0000000571 